\title{
Is an Engineering Project Management Degree Worth it? Developing Agile Digital Skills for Future Practice
}

\author{
Nicholas Dacre ", PK Senyo ", \& David Reynolds ${ }^{\circ}$ \\ a University of Southampton Business School, Southampton, UK nicholas.dacre@southampton.ac.uk \\ ${ }^{b}$ Henley Business School, University of Reading, Reading, UK prince.senyo@henley.ac.uk \\ c WMG, University of Warwick, Coventry, UK david.reynolds@warwick.ac.uk
}

\begin{abstract}
Engineering managers are progressively tasked with leveraging digital technologies and innovations which have yet to be fully developed, to seek out opportunities and challenges in complex project contexts. However, there is a disparity between knowledge gained from engineering development programmes, and the rapidly changing landscape of modern project practice, which requires professionals to effectively engage and deploy relevant agile digital skills in practice. For example, complex engineering projects increasingly employ dynamic digital technologies such as Artificial Intelligence (AI), Big Data, Augmented and Virtual Reality (AR / VR), 3D Printing, and Digital Twins, which require managers to quickly adapt to changing constraints through agile digital skills. Therefore, this paper seeks to focus on exploring the role of engineering project management programmes in developing knowledge and agile digital skills relevant for future project practice. Through an outline review of project management development programmes, this research paper suggests that their inherent value for engineering project managers, is largely dependent on a combination of applied research, engagement, and agile digital skills development for future practice.
\end{abstract}

Keywords: Project Management, Agile, Digital Skills, Al, Innovation, Project Manager, Engineering, Artificial Intelligence, Big Data, Augmented Reality, Virtual Reality, 3D Printing, Digital Twins, Digital, Technology, Engineering Manager.

\section{Cite this Paper}

Dacre, N., Senyo, PK., \& Reynolds, D. (2019). Is an Engineering Project Management Degree Worth it? Developing Agile Digital Skills for Future Practice. Engineering Education Research Network, Coventry, UK. https://dx.doi.org/10.2139/ssrn.3812764

\section{Introduction}

There has been considerable growth in engineering project management related development programmes which aim to equip future practitioners with the knowledge to address typical project-based challenges (Ojiako et al., 2011; Ramazani \& Jergeas, 2015). For example, higher education institutions offer an 
array of project related master degrees and bachelor programmes (de Valence, Best, \& Watt, 2007). These are generally embedded with subjects associated with project management practice, such as Business Management, Engineering, Operations, Strategy, Innovation, Construction, and IT, that reflect the discipline's interdisciplinary themes (Themistocleous \& Wearne, 2000). As such, there are an estimated 700 project management related masters courses available for university students to attend internationally, and in excess of 200 available in the UK (StudyPortals, 2019). However, engaging a broad spectrum of current and future practitioners can be challenging (Goswami \& Broadbent, 2017; Reynolds \& Dacre, 2019).

Project related development programmes are underpinned by buoyant employment opportunities with an average of 60,000 related jobs in the UK, and over 300,000 in the US (ZipRecruiter, 2019). Project management also plays a vital role for economic and social development, responsible for the employment of around 2.13 million full-time equivalent workers, and contributes an estimated $£ 156.5$ billion of gross value added to the UK economy (APM, 2019). However, solely leveraging core technical skills is seldom sufficient in responding to rapidly changing digital landscapes (PMI, 2018). For example, currently in excess of $80 \%$ of all job vacancies require some form of digital skills (Nania et al., 2019), and 82\% of project professional have identified digital skills as an important aspect for future practice (APM, 2019).

Although the demand for experienced project professionals with digital skills is resilient (APM, 2019; Kispeter, 2018; Nania et al., 2019; PMI, 2018), developing programmes which address future practice challenges remains challenging (Andrews \& Clark, 2017). Furthermore, there is a disparity between future project management agile digital skill requirements in an increasingly changing technology-driven innovative project landscape, and engagement approaches adopted in development programmes (Filippaios \& Benson, 2018; Ojiako et al., 2011; Ramazani \& Jergeas, 2015).

With a paucity of studies which specifically focus on the value of development programmes in response to future agile digital skill requirements, the main research focus of this paper is: "What is the role of engineering project management programmes in developing knowledge and agile digital skills relevant for future project practice?"

\section{Agile Digital Skills}

The context of digital engagement in the workplace is gaining momentum (Dacre, Constantinides, \& Nandhakumar, 2015), further raising a pressing need for digital skills in professional contexts (Kane et al., 2015). For example, the UK government commissioned a number of studies to identify potential digital skills gaps in the workforce, and the importance of digital skills development for the economy (Kispeter, 2018; Nania et al., 2019). These studies identified different levels of digital abilities across the workforce, ranging from novice to expert, however 
findings suggested that the impetus for digital skills largely remains constant regardless of experience or expertise.

Agile Digital Skills can be interpreted as the mediation between practitioners and innovative technologies such as Augmented and Virtual Reality (AR / VR), 3D Printing, Digital Twins, Big Data, and Artificial Intelligence (Al), and the ability to exploit these in order to capitalise on opportunities, and overcome challenges (APM, 2019; Filippaios \& Benson, 2018; Kispeter, 2018; Nania et al., 2019; PMI, 2018; Senyo, Liu, \& Effah, 2019). For example Al, which specifically employs agile digital skills, is increasingly permeating into modern project related practice (Cakmakci, 2019; Dam et al., 2018; Nicholls, 2017).

The concept of Al was originally coined by John McCarthy back in 1956 (McCarthy et al., 2006) in an attempt to ascertain whether computers could reason like a human, since then there have been two notable periods of low development and limited research engagement referred to as AI Winters. Largely occurring between 1970s and 1980s, and secondly between 1990s and 2000s (Grudin, 2009). However, nascent disruptive technological innovations and engagement with Big Data means that project professionals are increasingly stepping out of the Al winter into the 4th Industrial Revolution (Dam et al., 2018; Nicholls, 2017; Waboso, 2018).

The 4th Industrial Revolution represents the convergence of technology and innovation through the increasing digital transformation of organisations, services, and products (Skilton \& Hovsepian, 2017). Thus, the technological-driven resurgence of Al takes us from Machine

Learning to Machine Thinking, it provides an executive interface between project managers and Big Data and helps build better decision making bandwidth. However, although Al promises opportunities for project success, without project professionals' ability to expertly draw on agile digital skills in mediating this technology in project environments, risk of project failure remains a mitigating factor. Therefore, these disruptive technologies in project contexts require project management development programmes which address the increasingly agile set of digital skills and expert knowledge required in order to fully leverage potential opportunities and mitigate risks and challenges in future practice.

\section{Project Development Programmes}

Project based development programmes are inherently challenging and difficult to design, and implement to fully engage an interdisciplinary audience (Ojiako et al., 2011). In their metaanalysis of 8 years of engineering education studies, Andrews and Clark (2017) suggest five key areas in making programmes relevant for future engineering practitioners; (i) Accreditation, (ii) Active Learning, (iii) Core Technical Skills, (iv) Transferable Competencies, and understanding the (v) Engineering Context. Adopting (i) an accreditation process into programmes offers quality guidelines, (ii) active learning reflects a dynamic engagement context, (iii) core technical skills represents fundamental future problem solving approaches, (iv) 
transferable competencies encompass broader softer skills, and the (v) engineering context outlines the environment.

The concept of core skills is particularly relevant to agile digital skills development, however Andrews and Clark (2017) recognise the acute challenges in embedding these competencies for future practice with limited resources. Furthermore, the relationship between knowledge expertise of educators and the ensuing ability of their audience to engage with technologically challenging concepts, where the former lack confidence in more advanced aspects of a subject, can adversely affect the transfer of knowledge and emphasis of skills development (Jones, 2017).

There is also evidence from extant studies that suggests that "an academic's experience in industry also influences their judgements on the importance of professional skills" (Beagon \& Bowe, 2018, p. 67). Finally, the changing nature of technology, its interpretation, use and implementation, inherently reflects its evolution in both theory and practice (Blacklock, 2018; Budu, 2018; Malik, 2017), and despite this mandate for project related management development programmes, research suggests that historical approaches require appraisal anew (Ramazani \& Jergeas, 2015; Winter et al., 2006).

\section{Discussion}

The discipline of project management has been historically embedded in practice through the development and implementation of methodologies such as PRINCE2, links with the Association for Project Management, and the Project Management Institute. Given the historical nature of engineering project management as practice-driven, an opportunity for a research driven approach is apt and refreshing.

From the extant engineering related project management and agile digital skills literature, there are indications that a synergy between these two areas may lead to the development appropriate knowledge relevant for future projects. While there is great potential for using project management to develop knowledge and agile digital skills- based projects there are a number of issues that need attention.

First, there is a need for research informed engineering project management programmes. Given that project management is practice driven, there is a tendency of programmes to focus on anecdotal evidence from practical issues. However, to ensure that engineering project management programmes are relevant for future projects, there is a need for programme development to be driven by research informed evidence. With this, future practitioners will be exposed to current issues that are relevant to practice instead of relying on anecdotal evidence. In addition, using research informed evidence will enable better understanding and knowledge assimilation as real-world examples can be used in delivery of the programme. 
Second, there is a need for deliberate inclusion of areas on emerging technologies such as AI, VR and Big Data and 3D Printing (Senyo et al., 2019) in engineering project management programmes. Largely, project management programmes are not designed with strong emphasis on gaining a holistic skill on the use of emerging technologies. Whereas project management programmes traditionally offer some agile digital skills, the noteworthy opportunity in recent times now calls for deliberate inclusion and focus on emerging technologies. With this, engineering project management programmes will then offer more agile digital skills in addition to project management knowledge that are relevant for future practice.

Lastly, there is a need for engineering project management programmes to be designed to allow seamless transition from theory and practice and vice-versa. Learning and acquiring theoretical knowledge about emerging technologies is a good starting point. However, there is a need for opportunity to put this knowledge to practice. More often, actors do not have the opportunity to practice theoretical knowledge acquired. However, research has shown that learning is more effective if theory and practice are linked (Andrews \& Clark, 2017).

Thus, for engineering project management project programmes to be effective in developing knowledge and agile digital skills, there is a need for a medium for the application of theoretical knowledge. For example, the use of business and project simulation games can help bridge theory and practice (Petri et al., 2019; Pontin \& Adigun, 2019), and the concept of gamification which is the use of game elements in non-game contexts (Deterding et al., 2011) has been shown to have positive aspects on motivation and engagement (Dacre et al., 2015; Dacre, Gkogkidis, \& Jenkins, 2018). Prior studies also suggest that the concept of developing programmes in partnership with stakeholders can support a synchronous relation with future professionals, helping to not only engage them, but also underpin the nature and structure of the programme in order to address their expectations (Dacre et al., 2018).

\section{Conclusion}

The discussion in this paper suggest that historical project management development approaches which employ limited use of innovative learning techniques, offer a narrow platform upon which practitioners may develop the necessary agile digital skills to respond to rapidly changing digital landscapes.

Equally the relationship between theory and practice is acute in the field of project management, in that "in a fast, changeable and digital world, the cooperation between industry and academia is essential to prepare the students to a successful employment" (Cruz \& Saunders-Smits, 2017, p. 66). It is therefore important for project management programmes to ensure students develop practice-based transferable and critical thinking skills to adapt to rapidly changing technological environments.

The review of agile digital skills, suggest that these play a vital role in seeking opportunities and overcoming challenges by proactively leveraging innovative 
technologies in rapidly changing project contexts. For example, in this study we positioned the development of agile digital skills as one of innovation and control, in that this suggests an actor's ability to proactively influence innovative technologies and adapt to changing digital landscapes with agility. Thus, this study argues that in the context of engineering project management, practitioners should engage with agile digital skills development to leverage the benefits derived from innovative technologies for future practice. However, future practitioners are expected to develop knowledge and agile digital skills for practice which has yet to be developed. Thus, the matter of relevance for practice emerging from theoretical frameworks and knowledge expertise which may underpin the core essential project management capabilities, remains salient in preparing future project practitioners (Andrews \& Clark, 2017; PMI, 2018).

In order to address the main research focus of this paper, practically there is a need for engineering project management programmes to address future business needs by offering applied research and agile digital skills. In addition, project management programmes should offer knowledge that is domain independent and can be applicable in diverse areas. Moreover, project management programmes should be solution oriented to address future practical business problems.

Given that this study represents a foundation for future debates, the areas of engineering project management and emerging technologies offer several avenues for ensuing studies. First, future research may explore potential solutions emerging technologies can be used to develop engineering project management. In addition, further studies may investigate the impact of emerging technologies on engineering project management. Similarly, there is need to understand how organisations adopt and us emerging technologies in projects. Finally, future research may explore governance and regulatory issues on the use of emerging technologies in project management.

\section{References}

Andrews, J., \& Clark, R. (2017). Practice - v - Professionalism: Challenging the Status-Quo! Paper presented at the Annual UK \& Ireland Engineering Education Research Network Symposium.

APM. (2019). The Golden Thread: A Study of the Contribution of Project Management and Projects to the UK's Economy and Society Association for Project Management. UK.

Beagon, U., \& Bowe, B. (2018). The Academic Perspective: A Study of Academic Conceptions of the Importance of Professional Skills in Engineering Programmes in Ireland. Paper presented at the Spring Colloquium of the UK \& Ireland Engineering Education Research Network Symposium.

Blacklock, M. (2018). Blending Theory, Software and Practice: An Elemental Shift in Engineering Education. Paper presented at the Spring Colloquium of the UK \& Ireland Engineering Education Research Network Symposium.

Budu, J. (2018). Applying Agile Principles in Teaching Undergraduate Information Technology Project Management. International Journal of Information and Communication Technology Education (IJICTE), 14(3), 29-40. http://dx.doi.org/10.4018/IJICTE.2018070103 
Cakmakci, M. (2019). Interaction in Project Management Approach Within Industry 4.0 Advances in Manufacturing II (pp. 176-189): Springer. http://dx.doi.org/10.1007/978-3-03018715-6_15

Cruz, M. L., \& Saunders-Smits, G. N. (2017). Comparison of Transversal Competence Levels of Engineering Students With Labour Market Requirements. Paper presented at the Annual UK \& Ireland Engineering Education Research Network Symposium.

Dacre, N., Constantinides, P., \& Nandhakumar, J. (2015). How to Motivate and Engage Generation Clash of Clans at Work? Emergent Properties of Business Gamification Elements in the Digital Economy. International Gamification for Business Conference, Birmingham, UK. https://dx.doi.org/10.2139/ssrn.3809398

Dacre, N., Gkogkidis, V., \& Jenkins, P. (2018). Co-Creation of Innovative Gamification Based Learning: A Case of Synchronous Partnership. Society for Research into Higher Education, Newport, Wales UK. https://dx.doi.org/10.2139/ssrn.3486496

Dam, H. K., Tran, T., Grundy, J., Ghose, A., \& Kamei, Y. (2018). Towards effective Al-powered agile project management. arXiv preprint arXiv:1812.10578.

de Valence, G., Best, R., \& Watt, C. (2007). Project Management Education: Opportunities and Challenges. Paper presented at the ICAN Conference Sydney.

Deterding, S., Dixon, D., Khaled, R., \& Nacke, L. (2011). From game design elements to gamefulness: defining gamification. Paper presented at the Proceedings of the 15th International Academic MindTrek Conference: Envisioning Future Media Environments. http://dx.doi.org/10.1145/2181037.2181040

Filippaios, F., \& Benson, V. (2018). Agile Digital Skills Examination for the Digital Economy: Knowledge and Social Capital Management Frameworks through Social Networking The Future of Innovation and Technology in Education: Policies and Practices for Teaching and Learning Excellence (pp. 55-69): Emerald Publishing Limited. http://dx.doi.org/10.1108/978-1-78756-555520181006

Goswami, D., \& Broadbent, R. (2017). Enhancing student engagement and active participation via a flipped learning approach Paper presented at the Annual UK \& Ireland Engineering Education Research Network Symposium.

Grudin, J. (2009). Al and HCl: Two fields divided by a common focus. Al magazine, 30(4), 4848. http://dx.doi.org/10.1609/aimag.v30i4.2271

Jones, L. C. R. (2017). The Knowledge Mis-Alignment Between Engineering and Secondary School Technology Education Paper presented at the Annual UK \& Ireland Engineering Education Research Network Symposium.

Kane, G. C., Palmer, D., Phillips, A. N., \& Kiron, D. (2015). Is your business ready for a digital future? Mit Sloan Management Review, 56(4), 37.

Kispeter, E. (2018). What Digital Skills do Adults Need to Succeed in the Workplace Now and in the Next 10 Years? Warwick Institute for Employement Research. UK.

Malik, M. (2017). Meta-analysis and review of the use of Artificial Intelligence and Learning Analytics within Engineering Education at University level. Paper presented at the Annual UK \& Ireland Engineering Education Research Network Symposium. 
McCarthy, J., Minsky, M. L., Rochester, N., \& Shannon, C. E. (2006). A proposal for the dartmouth summer research project on artificial intelligence, august 31,1955 . Al magazine, 27(4), 12-12.

Nania, J., Bonella, H., Restuccia, D., \& Taska, B. (2019). No Longer Optional: Employer Demand for Digital Skills UK Government Department for Digital Culture Media \& Sport. UK.

Nicholls, D. (2017). Future of Project Management. ARUP.

Ojiako, U., Ashleigh, M., Chipulu, M., \& Maguire, S. (2011). Learning and teaching challenges in project management. International Journal of Project Management, 29(3), 268-278.

http://dx.doi.org/10.1016/j.ijproman.2010.03.008

Petri, G., von Wangenheim, C. G., Hauck, J. C. R., \& Borgatto, A. F. (2019). Effectiveness of Games in Software Project Management Education: An Experimental Study. Journal of Universal Computer Science, 25(7), 840-864. http://dx.doi.org/10.3217/jucs-025-07-0840

PMI. (2018). The Project Manager of the Future: Developing Digital-Age Project Management Skills to Thrive in Disruptive Times PMI. USA.

Pontin, D., \& Adigun, L. (2019). The Value of Business Simulation Games to Enable Students to Acquire the Key Skills Employers Require. Engineering Education Research Network, Coventry, UK.

Ramazani, J., \& Jergeas, G. (2015). Project managers and the journey from good to great: The benefits of investment in project management training and education. International Journal of Project Management, 33(1), 41-52. http://dx.doi.org/10.1016/j.ijproman.2014.03.012

Reynolds, D., \& Dacre, N. (2019). Interdisciplinary Research Methodologies in Engineering Education Research. Engineering Education Research Network, Coventry, UK. https://dx.doi.org/10.2139/ssrn.3812769

Senyo, P. K., Liu, K., \& Effah, J. (2019). Digital business ecosystem: Literature review and a framework for future research. International Journal of Information Management, 47, 52-64. http://dx.doi.org/10.1016/j.ijinfomgt.2019.01.002

Skilton, M., \& Hovsepian, F. (2017). The 4th Industrial Revolution: Responding to the Impact of Artificial Intelligence on Business: Springer.

StudyPortals. (2019). Project Management Masters. Retrieved 26/09/2019, from www.mastersportal.com

Themistocleous, G., \& Wearne, S. (2000). Project management topic coverage in journals. International Journal of Project Management, 18(1), 7-11. http://dx.doi.org/10.1016/S02637863(99)00030-7

Waboso, D. (2018). The Robot Professional? The Role of Project Professionals in the Digital Future. Association for Project Management.

Winter, M., Smith, C., Morris, P., \& Cicmil, S. (2006). Directions for future research in project management: The main findings of a UK government-funded research network. International Journal of Project Management, 24(8), 638-649.

ZipRecruiter. (2019). Project Management Jobs. Retrieved 26/09/2019, from www.ziprecruiter.com 